\title{
EXISTENCE AND UNIQUENESS OF SOLUTIONS TO THIRD-ORDER BOUNDARY VALUE PROBLEMS: ANALYSIS IN CLOSED AND BOUNDED SETS
}

\author{
Saleh S. Almuthaybiri And Christopher C. TiSdell
}

\begin{abstract}
The aim of this work is to develop a fuller theory regarding the existence, uniqueness and approximation of solutions to third-order boundary value problems via fixed point methods. To develop this deeper understanding of qualitative properties of solutions, our strategy involves an analysis of the problem under consideration, and its associated operator equations, within closed and bounded sets. This enables our new results to apply to a wider range of problems than those covered in the recent literature and we discuss several examples to illustrate the nature of these advancements.
\end{abstract}

Mathematics subject classification (2010): 34B15.

Keywords and phrases: Third-order boundary value problem, existence, uniqueness and approximation of solutions, contraction mappings, fixed point theorems, closed and bounded sets, two and three-point boundary conditions.

\section{REFERENCES}

[1] Tisdell, Christopher C., Critical perspectives of the 'new' difference equation solution method of Rivera-Figueroa and Rivera-Rebolledo, Internat. J. Math. Ed. Sci. Tech., 50, 1(2019) 160-163, https://doi.org/10.1080/0020739X.2018.1469796.

[2] Tisdell, Christopher C., On Picard's iteration method to solve differential equations and a pedagogical space for otherness, Internat. J. Math. Ed. Sci. Tech., 50, 5(2019) 788-799, https://doi.org/10.1080/0020739X.2018.1507051.

[3] TISDELL, CHRISTOPHER C., Rethinking pedagogy for second-order differential equations: a simplified approach to understanding well-posed problems, Internat. J. Math. Ed. Sci. Tech., 48, 5(2017) 794-801, https://doi.org/10.1080/0020739X.2017.1285062.

[4] Zhao, Li And Wang, Weixuan And Zhai, Chengbo, Existence and uniqueness of monotone positive solutions for a third-order three-point boundary value problem, Differ. Equ. Appl., 10, 3(2018) 251-260, https://doi.org/10.7153/dea-2018-10-18.

[5] Rus, IoAn A., On a fixed point theorem of Maia, Studia Univ. Babeş-Bolyai Math., 22, (1977) 40-42.

[6] Fahri Aktaş, Mustafa And ÇAKmaK, Devrim, Lyapunov-type inequalities for third-order linear differential equations under the non-conjugate boundary conditions, Differ. Equ. Appl., 10, 2(2018) 219-226, https: //doi.org/10.7153/dea-2018-10-14.

[7] Henderson, Johnny and luca, Rodica and Nelms, Jr., Charles and Yang, Aijun, Positive solutions for a singular third order boundary value problem, Differ. Equ. Appl., 7, 4(2015) 437-447, https://doi .org/10.7153/dea-07-25.

[8] Džurina, JozeF AND Baculíková, Blanka, Oscillation of third-order quasi-linear advanced differential equations, Differ. Equ. Appl., 4, 3(2012) 411-421, https://doi.org/10.7153/dea-04-23.

[9] Su, Mingmei And Xu, Zhiting, Oscillation criteria of certain third order neutral differential equations, Differ. Equ. Appl., 4, 2(2012) 221-232, https://doi .org/10.7153/dea-04-13.

[10] SMirnov, SERGEy, Green's function and existence of a unique solution for a third-order three-point boundary value problem, Math. Model. Anal., 24, 2(2019) 171-178. 
[11] Rogers, L. J., An extension of a certain theorem in inequalities, Messenger of Math., 17, (1888) $145-150$.

[12] Hoelder, O., Ueber einen Mittelwertsatz (German), J Goett. Nachr., (1889) 38-47.

[13] BANACH, STEFAn, Sur les opérations dans les ensembles abstraits et leur application aux équations intégrales, Fund. Math., 3, (1922) 133-181.

[14] Almuthaybiri, Saleh S. AND Tisdell, Christopher C., Sharper Existence and Uniqueness Results for Solutions to Third-Order Boundary Value Problems, Math. Model. Anal., 25, 3(2020) 409420, https://doi.org/10.3846/mma.2020.11043.

[15] Nirenberg, Louis, Partial differential equations in the first half of the century, Development of mathematics 1900-1950 (Luxembourg, 1992), Birkhäuser, Basel, (1994) 479-515.

[16] Zeidler, Eberhard, Nonlinear functional analysis and its applications. I, Fixed-point theorems, Translated from the German by Peter R. Wadsack, Springer-Verlag, New York, (1986), xxi+897.

[17] Stinson, Charles P. And Almuthaybiri, Saleh S. And Tisdell, Christopher C., A note regarding extensions of fixed point theorems involving two metrics via an analysis of iterated functions, Proceedings of the 14th Biennial Engineering Mathematics and Applications Conference, EMAC2019, Anziam J., 61 (2020) C15-C30, http://journal . austms .org.au/ojs/index.php/ANZIAMJ/article/view/15048.

[18] Tisdell, Christopher C., Pedogogical perspectives on the method of Wilmer III and Costa for solving second-order differential equations, Internat. J. Math. Ed. Sci. Tech., 50, 4(2019) 629-635, https://doi.org/10.1080/0020739X.2018.1480811.

[19] Tisdell, CHRISTOPHER C., Tic-Tac-Toe and repeated integration by parts: alternative pedagogical perspectives to Lima's integral challenge, Internat. J. Math. Ed. Sci. Tech., 51, 3(2020) 424-430, https://doi.org/10.1080/0020739x.2019.1620969.

[20] Tisdell, Christopher C., Pedagogical alternatives for triple integrals: moving towards more inclusive and personalized learning, Internat. J. Math. Ed. Sci. Tech., Taylor \& Francis, 49, 5(2018) 792-801, https://doi .org/10.1080/0020739X.2017.1408150.

[21] Tisdell, Christopher C., An accessible, justifiable and transferable pedagogical approach for the differential equations of simple harmonic motion, Internat. J. Math. Ed. Sci. Tech., Taylor \& Francis, 50, 6(2019) 950-959, https ://doi .org/10.1080/0020739X.2018.1516826.

[22] Tisdell, Christopher C., Critical perspectives of pedagogical approaches to reversing the order of integration in double integrals, Internat. J. Math. Ed. Sci. Tech., Taylor \& Francis, 48, 8(2017) 1285-1292, https://doi.org/10.1080/0020739X.2017.1329559. 